\title{
Orcein staining of hepatitis B antigen in paraffin sections of liver biopsies
}

\author{
K. P. DEODHAR, E. TAPP, AND P. J. SCHEUER
}

From the Departments of Pathology, Royal Free Hospital, London, and Withington Hospital, Manchester

SYNOPSIS Liver biopsies from 97 hepatitis B antigen $\left(\mathrm{HB}_{\mathrm{B}} \mathrm{Ag}\right)$-positive patients were stained by modified orcein method described by Shikata et al (1974) in order to detect the antigen in liver tissuẹ: The results were consistently negative in acute hepatitis, but positive in nearly two-thirds of biopsios from 53 patients with chronic liver disease. The distribution of positive staining was frequent irregular so that there is a problem of sampling error in needle biopsies. The deposits were seen in the cytoplasm of liver cells and occasionally in Kupffer cells, but never in nuclei. There was ac inverse relationship between staining and parenchymal necrosis. Biopsies from asymptomat $\mathrm{HB}_{\mathrm{s}} \mathrm{Ag}$ carriers were often strongly positive, as were 'ground-glass' hepatocytes in carriers ane patients with chronic liver disease. The mechanism of staining is unclear but may be related to theg presence of disulphide bonds in $\mathrm{HB}_{\mathrm{s}} \mathrm{Ag}$. The technique is simple and of use both in fresh and stores़् material.

Although more than 10 years have elapsed since the discovery of hepatitis $\mathrm{B}$ antigen $\left(\mathrm{HB}_{\mathbf{s}} \mathrm{Ag}\right)$ (Blumberg, 1964), its localization in tissues has hitherto remained a complicated procedure, requiring immunofluorescence or electron microscopy. Recently, however, Shikata, Uzava, Yoshiwara, Akatsuka, and Yamazaki (1974) have developed simple histochemical methods for the demonstration of $\mathrm{HB}_{\mathbf{s}} \mathrm{Ag}$ in conventional paraffin sections. The mechanism is apparently based on the presence of disulphide bonds in $\mathrm{HB}_{\mathrm{s}} \mathrm{Ag}$ (Vyas, Rao, and Ibrahim, 1972a; Sukeno, Shirachi, Yamaguchi, and Ishida, 1972). This paper reports the results of staining by one method described by Shikata et al (1974) in liver biopsies from patients with acute and chronic liver disease and from asymptomatic carriers of the antigen.

\section{Material and Methods}

Ten of the patients who underwent liver biopsy were from the Withington Hospital, Manchester, and the remainder from the Royal Free Hospital, London.

The liver biopsies studied, 12 of them operative wedge biopsies and the remainder percutaneous needle biopsies, were from 148 patients whose overall clinico-pathological diagnoses are shown in table I.

Received for publication 16 October 1974.

\begin{tabular}{|c|c|c|}
\hline \multirow[t]{2}{*}{ Disease Group } & \multicolumn{2}{|c|}{ Serum $H B_{\mathbf{s}} A g$} \\
\hline & + & - \\
\hline $\begin{array}{l}\text { Acute hepatitis } \\
\text { Chronic liver disease } \\
\text { HB }_{\text {s Ag carriers }}\end{array}$ & $\begin{array}{l}33 \\
53 \\
11\end{array}$ & $\begin{array}{r}25 \\
26 \\
0\end{array}$ \\
\hline Total & 97 & 51 \\
\hline
\end{tabular}

Table I Clinico-pathological diagnosis in 148 patients studied

Of the 97 seropositive patients, 33 had acute hepatitis of varying severity, and 53 had chronio liver disease. Five of the latter group were asymptos matic and detected on routine examination. Sever symptom-free patients were shown to have histolos gically near-normal livers. Four further patients ha\& jaundice subsequently shown to be due to biliarfs obstruction. The control group of biopsies was frort 25 patients with acute hepatitis and 26 with chronio liver disease (table I).

All slides were stained by a modification of the orcein stain for elastic tissue (Shikata et al, 1974) The method differed slightly from the published one The oxidizing solution used by us consisted of $0 \cdot 15 \overline{\mathbf{Q}}$ potassium permanganate, $100 \mathrm{ml}$ distilled water, an $0.015 \mathrm{ml}$ concentrated sulphuric acid. Sections wero decolourized in $2 \%$ oxalic acid for 10 minutes. The differentiating medium was $1 \%$ acid alcohol instea of absolute alcohol. 
Material believed to be the antigen was seen as dark brown or purple deposits within cells. The remainder of the tissue was very lightly stained. The number of orcein-positive cells, their distribution and intensity of staining, and the relationship of orcein-positive cells to necrosis were carefully noted.

\section{Results}

PREVALENCE OF ORCEIN-POSITIVE BIOPSIES IN DIFFERENT DISEASE GROUPS

All liver biopsies from the 51 patients seronegative with respect to $\mathrm{HB}_{\mathrm{s}} \mathrm{Ag}$ were also orcein-negative. The results of orcein staining in the 97 seropositive patients are given in table II. It will be seen that biopsies from patients in the acute stage of viral hepatitis were consistently negative. In chronic liver disease, on the other hand, a substantial proportion of biopsies were positive, both in chronic persistent hepatitis and in the more serious forms of chronic liver disease. Seven of the 11 carriers were positive, including two with biliary obstruction.

\begin{tabular}{lcrr}
\hline Diagnosis & Number & \multicolumn{2}{c}{ Orcein Stain } \\
\cline { 2 - 4 } & & \multicolumn{1}{c}{-} \\
\hline Acute hepatitis & 33 & 0 & 33 \\
Chronic persistent hepatitis & 11 & 7 & 4 \\
Chronic active hepatitis/cirrhosis & 40 & 27 & 13 \\
Liver cell carcinoma & 2 & 0 & 2 \\
HBsAg carriers & 11 & 7 & 4 \\
Total & 97 & 41 & 56 \\
\hline
\end{tabular}

Table II Results of orcein staining in 97 seropositive patients

Information on the duration of antigenaemia was available in 54 patients. Liver biopsies from nine patients with transient antigenaemia, in whom the antigen was cleared from the blood within three months of the onset of hepatitis, were uniformly negative. Of the remaining patients, who had antigenaemia lasting for three months or more, 28 were orcein-positive.

LOCALIZATION OF ORCEIN-POSITIVE STAINING The number of orcein-positive cells in each biopsy was very variable. In four biopsies only an occasional positive cell was seen in the slide. In the remaining biopsies several cells were found per high-power field. The number of orcein-positive cells was appreciably higher in those biopsies showing a 'ground-glass' appearance of the hepatocytes, as described below. The pattern of staining also varied. In two biopsies the staining was diffuse throughout

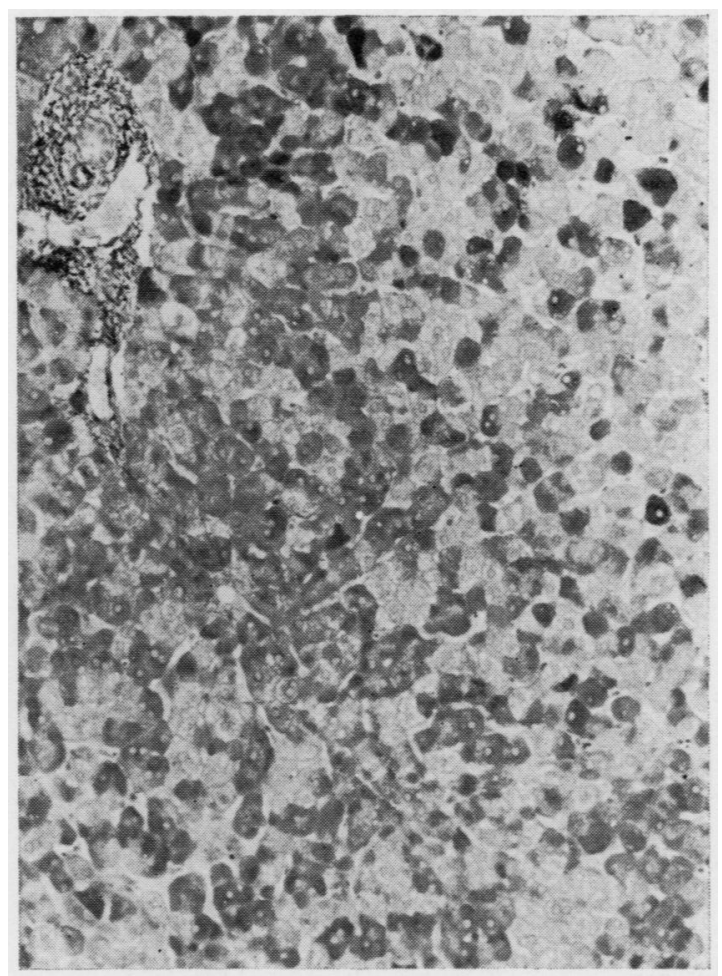

Fig 1 Liver biopsy from asymptomatic $\mathrm{HB}_{8} \mathrm{Ag}$ carrier. There is widespread ('diffuse') staining of hepatocytes. Nuclei are unstained. A portal tract is seen top left. (orcein $\times 135)$.

large areas of parenchyma (fig 1), while in 35 biopsies the staining was spotty, that is to say, orcein-positive material was found in isolated liver cells lying amongst orcein-negative cells (fig 2). In four biopsies both patterns were found. Although the intensity of staining was rather weaker in a few biopsies, it was never difficult to identify orceinpositive cells at low power. The staining was most intense in those biopsies with 'ground-glass' hepatocytes.

In all biopsies the orcein-positive material was present in the cytoplasm of some of the liver cells. Nuclear staining was never seen. In seven biopsies positive material was also seen in a few Kupffer cells; six of these biopsies were from patients with chronic liver disease and one was from a symptomless carrier.

In some biopsies large areas of negative staining were seen adjacent to positive areas (fig 3 ). In some cases the negative areas had the appearance of actively regenerating liver tissue, with compression of adjacent parenchyma. There was generally an 


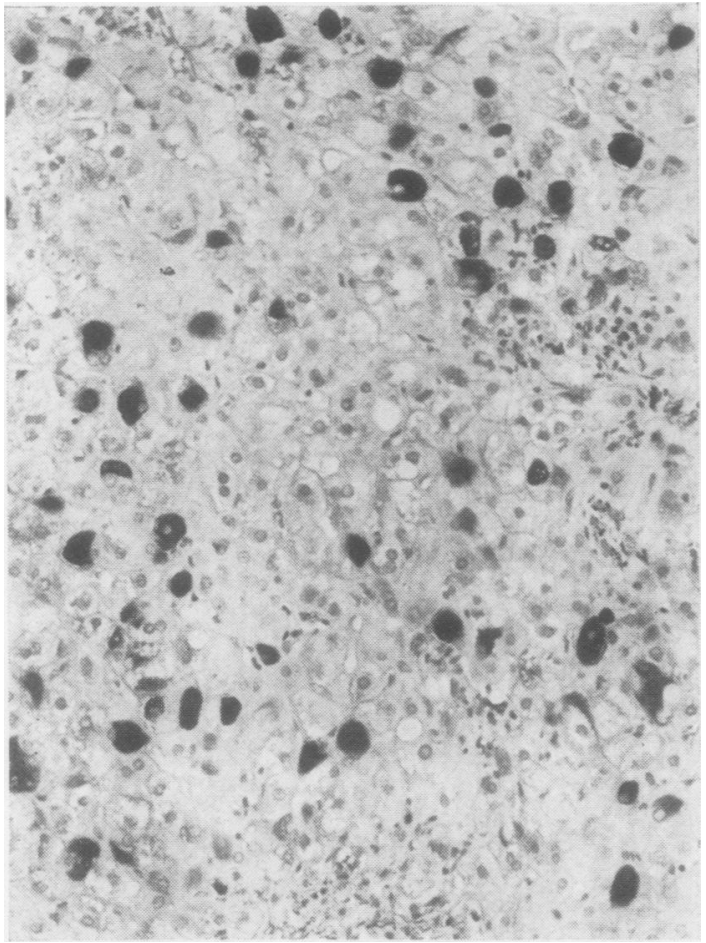

Fig 2

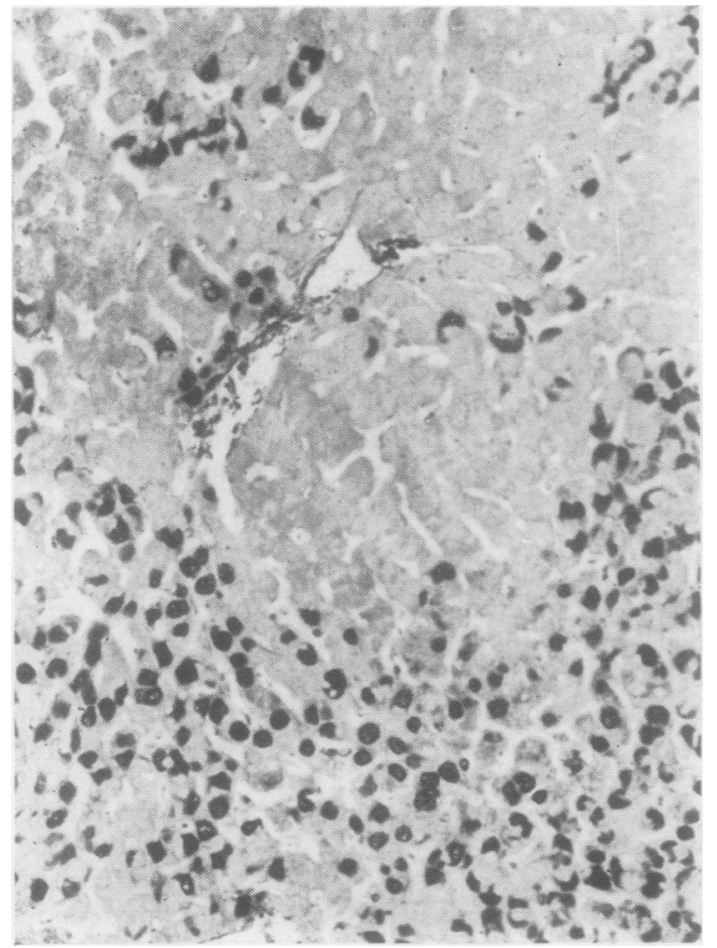

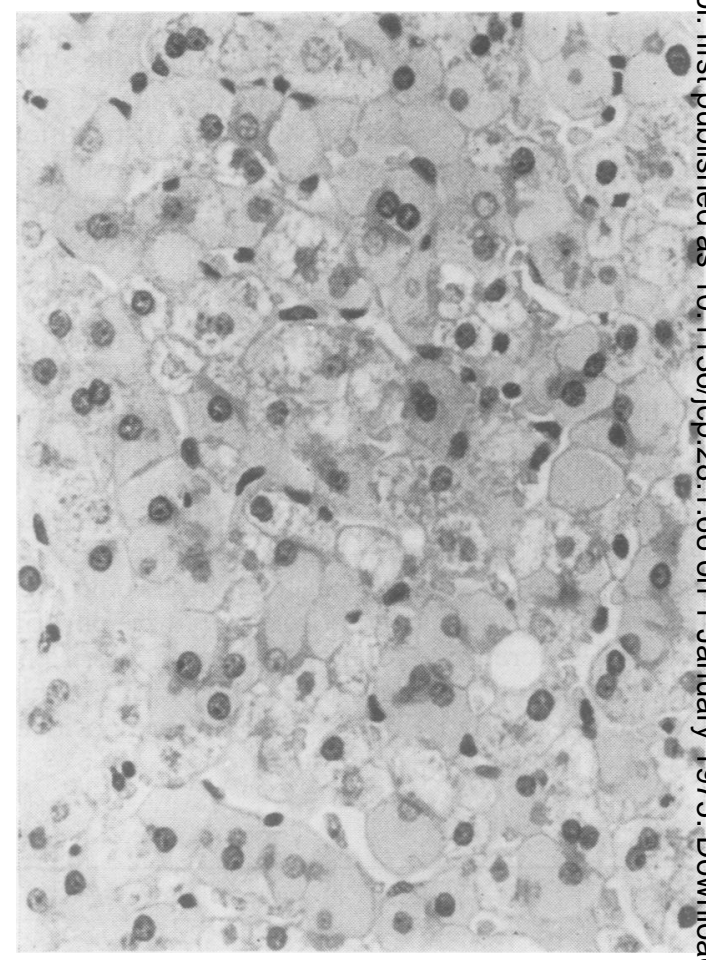

Fig 4

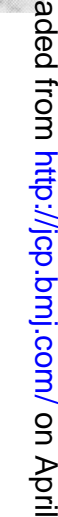

Fig 2 Chronic active hepatitis. Spotty distribution of orcein-positive cells (orcein $\times 165$ ). Fig 3 Orcein-positive cells are unequally distributed in $\stackrel{N}{N}$
this cirrhotic liver (orcein $\quad 165$ ).

Fig 4 Many liver cells in this biopsy from a symptomles $H B_{s} \mathrm{Ag}$ carrier have a 'ground-glass' appearance (haematoxylin and eosin $\times 336$ ).

Fig 3 
inverse relationship between necrosis of liver cell and orcein positivity. As noted above, the 33 biopsies from patients with acute hepatitis were negative, and in orcein-positive biopsies from chronic liver disease no positive staining was seen in areas of piecemeal necrosis. Acidophilic bodies were also negative.

RELATIONSHIP OF POSITIVE STAINING TO 'GROUND-GLASS' HEPATOCYTES

In 16 of the 41 orcein-positive biopsies some of the hepatocytes had the 'ground-glass' appearance described by Hadziyannis, Gerber, Vissoulis, and Popper (1973). Five of these biopsies were from asymptomatic carriers of the antigen (fig 4). In one carrier with biliary obstruction subsequently shown to be due to carcinoma of the pancreas, the presence of 'ground-glass' cells supported the view that the patient's jaundice was not due to acute hepatitis. 'Ground-glass' liver cells were never found in orcein-negative biopsies, and were seen to be orcein-positive (fig 1).

\section{RESULTS IN PATIENTS WITH MULTIPLE BIOPSIES}

Thirteen follow-up liver biopsies were available for study from 11 patients. Of the 10 patients in whom only one additional biopsy was performed, seven remained orcein-positive. Two were both seronegative and orcein-negative and the third orcein-negative patient had active cirrhosis with much necrosis. One patient with active cirrhosis was biopsied on four occasions and orcein-positive cells were seen in only one biopsy showing relatively mild liver damage.

\section{Discussion}

The original observation by Shikata et al (1974) that some cells in the livers of patients with chronic liver diseases stained with the elastic Van Gieson sta in was made accidentally. These authors then suggested that the apparent affinity of $\mathrm{HB}_{\mathrm{s}} \mathrm{Ag}$ to dyes such as Alcian blue and Gomori's aldehyde fuchsin was due to the presence of disulphide bonds, since the antigen has been shown to have high levels of cystine (Dreesman, Hollinger, Suriano, Fujioka, Brunschwig, and Melnick, 1972; Vyas, Williams, Klaus and Bond, 1972b). It is believed that disulphide bonds play an important role in antigenicity and particle size of $\mathrm{HB}_{\mathbf{s}} \mathrm{Ag}$ (Sukeno et al, 1972; Vyas et al, 1972a). The orcein stain also has an affinity for other structures rich in disulphide bonds, such as the keratin of the hair follicles. More direct evidence that it is the antigen that is stained with orcein is the close correspondence found between positive staining and specific immunofluorescence for $\mathrm{HB}_{\mathrm{s}} \mathrm{Ag}$
(Shikata et al, 1974; Gerber, Vernace, and Popper, 1974). In three of our orcein-positive biopsies the presence of $\mathrm{HB}_{\mathrm{s}} \mathrm{Ag}$ in hepatocytes was confirmed by electron microscopy.

In our study the orcein method was consistently negative in acute hepatitis, but useful for detecting the antigen in a variety of chronic liver diseases. Even in orcein-positive biopsies, the staining was confined to areas showing little or no necrosis, in keeping with the findings of Krawczynski, Nazarewicz, Brzosko, and Nowoslawski (1972) that there are larger quantities of $\mathrm{HB}_{\mathbf{s}} \mathrm{Ag}$ in apparently normal hepatocytes and in areas showing little or no parenchymal damage. There is a possible discrepancy between our results and those of Shikata et al (1974) in that the latter obtained $100 \%$ positive results in a group of patients including 'Au-positive hepatitis', but the proportion of patients with acute disease was not specified. Our lower positive results could perhaps be explained by sampling error, since the orcein-positive cells have been shown to be irregularly distributed within biopsies. However, it seems more likely that our consistently negative results in acute hepatitis, even in large biopsies, reflect genuine absence, paucity, or lack of staining of the antigen. This is consistent with the findings of Dudley, Fox, and Sherlock (1971) of an inverse relationship between the degree of liver cell damage and the titre of circulating antigen. However, Tapp, Jones, Anfield, Whittaker, Woolf, and Dymock (1974) found no such relationship in their patients. Hadziyannis, Vissoulis, Moussouros, and Afroudakis (1972) observed that the number of fluorescent liver cells and the intensity of fluorescence was much more in normal liver of carriers than in the damaged liver of patients with chronic hepatitis and cirrhosis. Moreover, Krawczynski et al (1972) failed to detect the antigen in nine biopsies from patients with fulminant hepatitis.

Sixteen of the 41 orcein-positive biopsies, including five from $\mathrm{HB}_{\mathrm{s}} \mathrm{Ag}$ carriers, contained typical 'groundglass' hepatocytes, as described by Hadziyannis et al (1973). These authors observed the cells in 18 of 19 biopsies from carriers and suggested that their presence in an otherwise normal liver should lead to a suspicion of the antigen carrier state. The results of orcein staining in our series tend to confirm the conclusion based on immunofluorescent studies (Hadziyannis et al, 1973) that the 'groundglass' hepatocytes are sites of abundant $\mathbf{H B}_{\mathbf{s}} \mathrm{Ag}$. Gerber, Hadziyannis, Vissoulis, Schaffner, Paronetto, and Popper (1973) also demonstrated that the 'ground-glass' cells may contain long filaments and 20 to $30 \mathrm{~nm}$ circular structures, possibly representing viral material, in the cisternae of the endoplasmic reticulum. Dane particles are rare in the serum of 
carriers with minimal histological lesions (Deutsch and Spence, 1972; Nielsen, Nielsen, and Elling, 1973) and it thus seems possible that in the carrier state infection has resulted in abundant formation of viral coat, but not core, without leading to cytopathogenic effects. The orcein stain seems to reveal coat rather than core antigen. This may explain our consistently negative results in acute hepatitis and the inverse relationship with parenchymal necrosis.

In conclusion, we believe that the method devised by Shikata et al (1974) shows $\mathrm{HB}_{\mathrm{s}} \mathrm{Ag}$ in the tissues. False negative results in chronic liver disease are most likely to be due to sampling error. The method should not be used for primary detection of $\mathrm{HB}_{\mathrm{S}} \mathrm{Ag}$ in patients; its value lies in the possibility of studying the localization of the antigen at a cellular level, and above all the opportunity to study stored material obtained from patients before its discovery. We have seen orcein-positive material in a liver biopsy stored since 1963 . Finally, the method has been used by us in differentiating acute hepatitis from the carrier state in an acutely jaundiced patient.

We are grateful to Dr Tohio Shikata of Tokyo for drawing our attention to the staining method and for giving us the details. We thank Professor S. Sherlock and Dr I. W. Dymock for allowing us to use clinical information on their patients, Professor S. Huang of Montreal for carrying out electron microscopy on one biopsy, and the Association of Commonwealth Universities for providing a grant to one of us (K.P.D.).

\section{References}

Blumberg, B. S. (1964). Polymorphisms of the serum proteins and the development of isoprecipitins in transfused patients. Bull. N.요하․ Acad. Med., 40, 377-386.

Deutsch, G. F., and Spence, L. (1972). Virus-like particles in the liver and their relationship to Australia antigen. Lancet, 1, 447.

Dreesman, G. R., Hollinger, F. B., Suriano, J. R., Fujioka, R. Brunschwig, J. P., and Melnick, J. L. (1972). Biophysical a biochemical heterogeneity of purified hepatitis $B$ antigen J. Virol., 10, 469-476.

Dudley, F. J., Fox, R. A., and Sherlock, S. (1971). Relationship $\mathbb{\Phi}_{f}$ hepatitis-associated antigen (H.A.A.) to acute and chronds liver injury. Lancet, 2, 1-3.

Gerber, M. A., Hadziyannis, S., Vissoulis, C., Schnaffner, F., Par netto, F., and Popper, H. (1973). Identification of cytoplasmif hepatitis $\mathbf{B}$ antigen in carriers by immuno-electron microscopy. Gastroenterology, 65, 541.

Gerber, M. A., Vernace, S., and Popper, H. (1974). Groundgl hepatocytes in hepatitis B antigen ( $\mathrm{HBAg}$ ) positive chrow hepatitis and cirrhosis. (Abstr.) Gastroenterology, 66, 885.

Hadziyannis, S., Gerber, M. A., Vissoulis, C. and Popper, H. (197B Cytoplasmic hepatitis B antigen in 'ground-glass' hepatocy?es of carriers. Arch. Path., 96, 327-330.

Hadziyannis, S., Vissoulis, C., Moussouros, A., and Afroudakis, (1972). Cytoplasmic localisation of Australia antigen in the liver. Lancet, 1, 976-979.

Krawczynski, K., Nazarewicz, T., Brzosko, W. J., and Nowoslawski A. (1972). Cellular localisation of hepatitis-associated antigen in livers of patients with different forms of hepatitis. J. infeegr. Dis., 126, 372-377.

Nielsen, J. O., Nielsen, M. H., and Elling, P. (1973). Differentma distribution of Australia-antigen-associated particles in pations with liver diseases and normal carriers. New Engl. J. Med., 288. 484-487.

Shikata, T., Uzawa, T., Yoshiwara, N., Akatsuka, T., and Yamazaf․ S. (1974). Staining methods of Australia antigen in paraftin section. Jap. J. exp. Med., 44, 25-36.

Sukeno, N., Shirachi, R., Yamaguchi, J., and Ishida, N. (1979). Reduction and reoxidation of Australia antigen: loss ald reconstitution of particle structure and antigenicity. J. Virg. 9, 182-188.

Tapp, E., Jones, D. M., Anfield, C., Whittaker, J. S., Woolf, I. and Dymock, I. W. (1974). Intranuclear particles in hepa cytes of HB Ag-positive blood donors. Lancet, 1, 934 .

Vyas, G. N., Rao, K. R., and Ibrahim, A. B. (1972a). Austratio antigen (hepatitis $B$ antigen): a conformational antigo dependent on disulphide bonds. Science, 178, 1300-1301.

Vyas. G. N., Williams, E. W., Klaus, G. G. B., and Bond, H. (1972b). Hepatitis-associated Australia antigen: prote peptides, and amino acid composition of purified antigen with its use in determining sensitivity of the hemagglutination J. Immunol., 108, 1114-1118. 